\title{
La cortesía verbal en Sófocles: análisis del optativo potencial en actos de habla directivos*
}

\author{
Luz Conti \\ Universidad Autónoma de Madrid \\ luz.conti@uam.es \\ ORCID iD: https://orcid.org/0000-0001-5264-0198 \\ Verbal Politeness in Sophocles: Analysis \\ of the Potential Optative in Directive Speech Acts
}

\begin{abstract}
El presente trabajo, centrado en las tragedias completas de Sófocles, analiza el uso del optativo potencial en actos de habla directivos. Las gramáticas analizan el optativo potencial en este tipo de actos de habla como una expresión de cortesía. No precisan, sin embargo, si el optativo tiene un funcionamiento idéntico en todos los contextos. El análisis de los datos seleccionados para este trabajo permite concluir que el uso del optativo en segunda persona refleja, en general, una estrategia de cortesía diferente del uso en primera y en tercera persona. De hecho, en segunda persona el optativo funciona en la mayor parte de los casos como una expresión convencional de cortesía. En primera y en tercera persona, por el contrario, el optativo ha de analizarse como una expresión de cortesía off record que tiene como fin reducir la implicación del interlocutor en el cumplimiento del contenido proposicional del acto de habla.
\end{abstract}

Palabras clave: Sófocles; optativo potencial; cortesía verbal; pragmática; sintaxis.
This paper, focused on the complete tragedies of Sophocles, analyses the use of potential optative in directive speech acts. Grammars analyse the potential optative in this type of speech acts as a politeness strategy. They do not determine, however, if it displays an identical functioning in all contexts. The analysis of the selected material allows to conclude that the use of the optative in the second person generally reflects a politeness strategy different from the strategy displayed both in the first and third person. In fact, in the second person the optative functions in most cases as a conventional expression of politeness. On the contrary, in the first and the third person the optative should be analysed as an off-record politeness expression that reduces the implication of the addressee in the fulfillment of the propositional content of the speech act.

Key words: Sophocles; potential optative; verbal politeness; Pragmatics; Syntax.

Cómo citar este artículo / Citation: Conti, Luz 2020: «La cortesía verbal en Sófocles: análisis del optativo potencial en actos de habla directivos», Emerita 88 (2), pp. 235-255.

* El presente trabajo se ha realizado en el marco del proyecto «Cortesía y descortesía verbal en el diálogo literario del griego antiguo» (PGC2018-093779-BI00). Agradezco a E. Crespo, R. Fornieles y E. Redondo sus críticas y comentarios. 


\section{INTRODUCCIÓN}

El análisis de la cortesía verbal, campo de estudio de la pragmática fraguado en los años setenta del s. XX, ha experimentado desde sus inicios un enorme desarrollo que continúa hasta el día de hoy. A pesar de las numerosas críticas, surgidas ya en los años noventa y presentes hasta la actualidad, los principios teóricos propuestos por Brown y Levinson 1987 constituyen el punto de partida de la mayoría de los trabajos centrados en la cortesía verbal ${ }^{1}$; en este sentido, los estudios del griego antiguo no son una excepción. Así, los conceptos de positive face y negative face siguen siendo la piedra de toque de los trabajos sobre la cortesía verbal. La imagen positiva se corresponde con la necesidad que tiene todo individuo de acercarse a su interlocutor y generar la idea de pertenencia a un mismo grupo. La imagen negativa, por el contrario, refleja la necesidad de mantener una esfera de intimidad y de espacio propio. Ante este conflicto entre intereses contrapuestos, el hablante puede primar uno de ellos, pero también escoger formulaciones neutras ${ }^{2}$.

Las estrategias de cortesía empleadas por el hablante dependen, en cada acto comunicativo, de la combinación de cinco parámetros ${ }^{3}$ :

1. Relación de poder entre los interlocutores (eje vertical) 4 .

2. Distancia social entre los interlocutores (eje horizontal).

3. Grado de amenaza que supone el acto de habla que se pretende formular.

4. Contexto lingüístico en el que se inserta una expresión dada.

5. Tipo de interacción mantenida por hablante e interlocutor.

En la interrelación de estos parámetros son esenciales tanto el peso de los códigos socioculturales compartidos por el hablante y su interlocutor ${ }^{5}$ como la situación o el contexto extralingüístico en la que se desarrolla el acto comunicativo ${ }^{6}$.

${ }^{1}$ En Kadar 2019 el lector encontrará una presentación detallada de las precisiones propuestas hasta ahora a la teoría de Brown y Levinson.

${ }^{2}$ Cf. Kerbrat-Orecchioni 1996, pp. 51-52.

${ }^{3}$ Cf., entre otros, Risselada 1993, pp. 6-10.

${ }^{4}$ Se ha de tener en cuenta que la relación de poder entre los interlocutores puede variar y está determinada por la situación concreta en la que se hallan uno y otro.

${ }^{5}$ Es decir, el llamado common ground (cf. Brown y Levinson 1987, pp. 103, 117, Clark y Carlson 1982 y Clark y Brennan 1991).

${ }^{6} \mathrm{El}$ contexto permite, por ejemplo, que algunos actos de habla considerados amenazantes puedan resultar neutros e incluso corteses en determinadas situaciones (cf. Watts 2003, p. 149 
Cuando el hablante considera que su acto de habla puede suponer una amenaza para el interlocutor, optará, siempre y cuando no tenga interés en preservar una relación comunicativa armoniosa, por formas de expresión directas e inequívocas (bald on record) $)^{7}$. Ahora bien, si desea preservar la armonía con su interlocutor, recurrirá a formas de expresión que aminoren la amenaza potencial del acto de habla. El hablante preferirá, en ocasiones, expresiones corteses de contenido claro, pero en otras puede considerar más conveniente el uso de expresiones imprecisas, de carácter implícito, que admitan una interpretación alternativa sin conexión alguna con un acto de habla amenazante (off record) $)^{8}$.

Los actos de habla indirectos, es decir, aquellos cuya fuerza ilocutiva no se corresponde con la que sugieren sus marcas gramaticales ${ }^{9}$, son un recurso muy empleado por los hablantes cuando desean aminorar el carácter amenazante de su mensaje. Sin embargo, en ocasiones los actos de habla indirectos no son percibidos por el receptor como expresiones de cortesía, sino de hipercortesía $^{10}$. Además, el hablante puede servirse de ellos cuando finge ser cortés, pero en realidad no lo es (mock politeness) ${ }^{11}$. Como vemos, la línea divisoria entre la cortesía y la descortesía no es, ni mucho menos, nítida.

\section{El OPTATIVO POTENCIAL COMO EXPRESIÓN DE CORTESÍA}

En griego antiguo, el optativo con ő́v, de valor potencial, se utiliza ya desde Homero como expresión de mensajes directivos.

ss.). El concepto de relational work, acuñado por Locher y Watts 2005, p. 9, ha sido el punto de partida de numerosos trabajos sobre la cortesía verbal en lenguas habladas.

7 Sobre los conceptos bald on record y off record véanse Brown y Levinson 1987, pp. 9498 y $211-212$.

${ }_{8}^{8}$ El talante del hablante frente a la relación armoniosa con su interlocutor ha sido definido por Spencer-Oatay 2008, p. 32 como rapport orientation. Como muestran Culpeper y Qian 2019 , las diferentes rapport orientations del hablante se traducen en formulaciones distintas para la expresión de un mismo contenido.

${ }^{9}$ Searle 1975.

${ }^{10}$ Sobre este concepto, cf. Kienpointner 1997, p 257. Locher 2004, p. 9 afirma de la hipercortesía: «(It is) often perceived as negative exactly because it exceeds the boundary between appropriateness and inappropriateness».

${ }^{11}$ Cf. Culpeper 1996, p. 356: «The FTA is performed with the use of politeness strategies that are obviously insincer, and thus remain surface realisations». 
En los poemas homéricos, el optativo con ờv se inserta en oraciones negativas de carácter interrogativo ${ }^{12}$ (1). En época clásica, sin embargo, son frecuentes los ejemplos de oraciones afirmativas con un carácter enunciativo o exclamativo, como la del pasaje de (2):

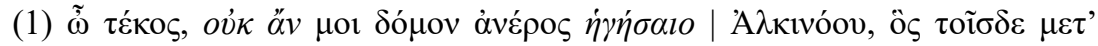

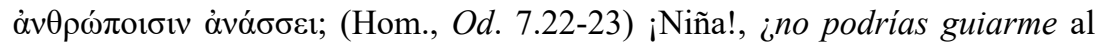
palacio de Alcínoo, que reina entre estos hombres?

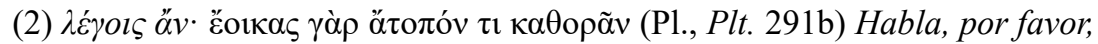
que parece que estás viendo algo insólito.

En general, se considera que el optativo con ớv de actos de habla indirectos es uno de los posibles recursos utilizados por el hablante para mitigar la fuerza impositiva de su mensaje y, en consecuencia, para expresarse con un tono cortés ante su interlocutor ${ }^{13}$. En este sentido, hemos de tener en cuenta que el optativo potencial presenta el cumplimiento de la acción verbal como algo posible, pero no como algo que está sucediendo de facto. Establece, pues, una clara distancia entre la realidad en el momento del acto de habla y la situación descrita en la oración ${ }^{14}$. El optativo con ớv deja abierto el cumplimiento de la acción verbal y permite, por tanto, que el interlocutor tenga, al menos en teoría, dos opciones: la de sentirse implicado y actuar y la de no hacerlo. Se trata, pues, de una fórmula sustitutiva idónea para el imperativo y el subjuntivo y, en determinados contextos, también para el futuro ${ }^{15}$.

Algunas expresiones de cortesía se convencionalizan por su frecuencia de uso. Pierden, por tanto, parte de su valor indirecto, ya que resultan inequívocas tanto para el hablante como para el oyente, aunque se utilizan con un significado que no es el literal ${ }^{16}$. Con este tipo de recursos, el hablante consigue un

12 Véanse, entre otros, Kühner y Gerth 1898, pp. 233-234 y Chantraine 1997², pp. 221-222. Como se observa en (1), se trata de oraciones en las que la negación tiene un carácter expletivo.

${ }^{13}$ Cf., entre otros, Kühner y Gerth 1898, pp. 233-236, Crespo, Conti y Maquieira 2003, pp. 294-295, Drummen 2013, pp. 89 ss. y van Emde Boas et al. 2019, pp. 441-442.

${ }^{14}$ Es, en términos de Kerbrat-Orecchioni 2004, p. 42, un desactualizador modal y temporal.

15 Sobre el valor directivo del futuro véanse, por ejemplo, Denizot 2011, pp. 433-437 y Allan 2017, pp. 53-56.

${ }^{16}$ Una oración como ¿Puedes pasarme la sal?, por ejemplo, tiene un valor directivo evidente. En el contexto apropiado, ningún hablante con competencia en castellano pensaría en el significado literal de poder + infinitivo. 
compromiso entre la eficacia comunicativa de las expresiones on record, que excluyen cualquier ambigüedad, y las expresiones off record, más útiles cuando el propósito es ser cortés ${ }^{17}$. Está por determinar si el optativo funciona en algunos contextos $-\mathrm{o}$ en todos - como expresión convencional de cortesía ${ }^{18}$.

Aunque Sófocles también ofrece ejemplos en los que el optativo parece funcionar como expresión de hipercortesía y de cortesía fingida ${ }^{19}$, el presente trabajo solo se centrará en aquellos casos en los que el optativo potencial admite un análisis como forma de cortesía. La relación entre el uso del optativo con ő́v en mensajes directivos y las estrategias de cortesía de los personajes de las tragedias completas de Sófocles no se ha tratado hasta ahora ${ }^{20}$.

\section{Objetivos del trabajo}

Sobre la base de los principios teóricos y los datos que acabamos de exponer, el presente trabajo, centrado en los diálogos de las tragedias de Sófocles que conservamos completas, se limitará al análisis del optativo potencial como expresión de cortesía en su uso en oraciones enunciativas ${ }^{21}$. Sus objetivos serán los siguientes:

1. Descripción de los rasgos sintácticos, semánticos y pragmáticos de las oraciones formuladas en segunda persona.

2. Determinación de los factores sintácticos, semánticos y pragmáticos que favorecen que, en la emisión de este tipo de actos de habla directivos, el hablante se dirija a su interlocutor en primera o en tercera persona, en lugar de hacerlo en segunda persona.

3. Descripción de las estrategias de cortesía que subyacen al uso del optativo en primera, en segunda y en tercera persona.

Es evidente que el estudio de la cortesía verbal y, en general, de la pragmática, es especialmente difícil en las lenguas de corpus. Con todo, esto no

${ }^{17}$ Cf. Brown y Levinson 1987, pp. 132-142.

${ }^{18}$ Hasta donde sabemos, esta cuestión aún no ha sido abordada.

19 Sobre la ironía en Sófocles véase Lloyd 2012.

${ }^{20}$ Drummen 2013 analiza el funcionamiento del optativo con ớv en una selección de comedias y de tragedias. En el caso de Sófocles, se centra en Antígona y Ayante, sin ahondar en cuestiones de cortesía verbal.

${ }^{21}$ Las oraciones exclamativas y las oraciones interrogativas, tanto retóricas como no retóricas, se dejarán fuera de consideración. 
impide llegar a conclusiones convincentes, como ya han demostrado trabajos anteriores $^{22}$.

\section{Presentación y ANÁLisis de LoS Datos}

El trabajo se ha centrado exclusivamente en las tragedias de Sófocles que conservamos completas y ha partido de los ejemplos en los que el optativo con ớv se utiliza, bien en oración independiente, bien en la oración principal de una estructura subordinada ${ }^{23}$. Tras excluir las oraciones condicionales, que serán tratadas en trabajos posteriores, se ha analizado un total de 226 pasajes. De entre ellos, se han seleccionado 25, que son los que admiten una interpretación como expresiones de actos de habla directivos, bien explícitos - o al menos inequívocos-, bien implícitos ${ }^{24}$.

Los actos de habla directivos se subdividen en órdenes, ruegos, peticiones, solicitud de permiso, concesión de permiso, consejos, sugerencias, invitaciones y propuestas ${ }^{25}$. Esta subdivisión se basa en dos parámetros ${ }^{26}$ :

1. La relación del contenido directivo con los intereses del hablante o con los del interlocutor ${ }^{27}$. Las órdenes, los ruegos, las peticiones y la solicitud de permiso están enfocados, básicamente, hacia los intereses del hablante; la concesión de permiso, los consejos, las sugerencias y las invitaciones, hacia

${ }^{22}$ Piénsese, por ejemplo, en los trabajos sobre Sófocles de Lloyd 2006 y 2012 y en el de Catrambone 2016, también centrado en Sófocles.

${ }^{23}$ La búsqueda y recopilación de los datos se ha llevado a cabo a través del Thesaurus Linguae Graeca, A Digital Library of Greek Literature (http://stephanus.tlg.uci.edu/Iris/inst/ tsearch.jsp). Las traducciones de los ejemplos son nuestras.

${ }^{24}$ Se trata de Ai. 213, Ai. 218, Ai. 525-526, Ai. 1339, Ai. 1342, Ant. 240, Ant. 444, Ant. 1339, El. 637, El. 1436, El. 1440, OC 580, OC 725, OC 1565-1567, OT 95, OT 205, OT 282, OT 570, OT 1045, OT 1053, OT 1445, Ph. 517, Ph. 674, Tr. 624, y Tr. 1154. En un grupo reducido de ejemplos, los personajes utilizan el optativo con ö $v$ para criticar al interlocutor y procurar que cambie una actitud con la que no están de acuerdo. Estos pasajes serán analizados en otro trabajo.

${ }^{25}$ Risselada 1993, pp. 45-49. Los actos de habla con los que el hablante pide permiso para actuar en algún sentido y los actos de habla con los que el hablante da permiso a su interlocutor no están incluidos en la clasificación de Risselada.

${ }^{26}$ Risselada 1993, pp. 46-49.

${ }^{27}$ Hemos de tener en cuenta que se trata de una orientación secundaria. Los actos de habla directivos están orientados de forma primaria hacia el interlocutor (cf. Haverkate 1984, pp. 66-78). 
los del receptor; las propuestas, por último, tienen presentes tanto los intereses del hablante como los de su interlocutor ${ }^{28}$.

2. El grado de coerción que ejerce el hablante sobre el interlocutor, es decir, la posibilidad que deja a este para reaccionar o no ante su mensaje. En este sentido, las órdenes, la concesión de permiso y los consejos se diferencian claramente de los demás subtipos de actos directivos, que permiten al receptor una mayor capacidad de acción.

Risselada 1993, pp. 42-43, distingue, además, un tipo de acto de habla directivo orientado a la tercera persona o sin orientación (cf. El niño tiene que hacerse la cama o Llamar antes de entrar).

Como veremos enseguida, las fronteras entre los diferentes subtipos de actos de habla directivos son laxas.

El optativo potencial no es, en principio, una forma de expresión idónea para las órdenes, pues, como acabamos de mencionar, deja cierta capacidad de maniobra al receptor del mensaje, al menos en teoría. Las peticiones y las sugerencias, por el contrario, parecen más adecuadas para su formulación en optativo.

El siguiente pasaje ofrece un ejemplo del uso del optativo en la expresión de lo que podríamos considerar una sugerencia. Neoptólemo se dirige a Filoctetes:

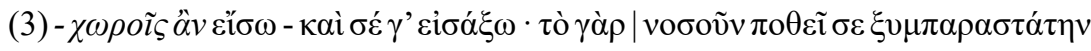
$\lambda \alpha \beta \varepsilon i v$ (S., Ph. 674-675) -Ne. Entra, por favor -Fi. Te llevo dentro conmigo, pues mi enfermedad exige que me ayudes.

Ahora bien, el optativo es también compatible con actos de habla directivos que suponen un mayor grado de coerción para el interlocutor. Centrémonos en dos ejemplos.

En los siguientes versos, Deyanira ordena al heraldo Licas que se dirija al encuentro de Heracles para darle las vestiduras que, como sabemos, habrán de matarlo:

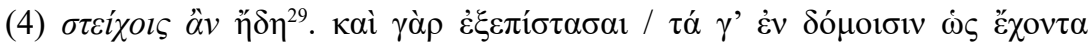

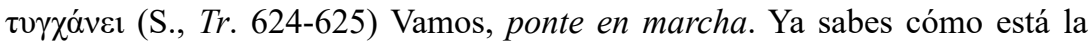
situación en casa.

${ }^{28}$ Risselada 1993, p. 47.

${ }^{29}$ En su uso como marcador del discurso, $\ddot{\delta} \eta$ tiene en ocasiones un valor interactivo

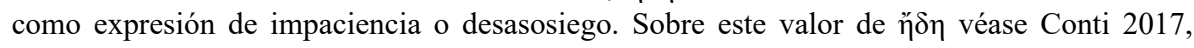
pp. $125-126$. 
En este otro pasaje, Creonte da permiso al guardián que ha sorprendido a Antígona para que se retire ${ }^{30}$. Obsérvese cómo, acto seguido, el rey se dirige a la joven mediante un imperativo ${ }^{31}$ :

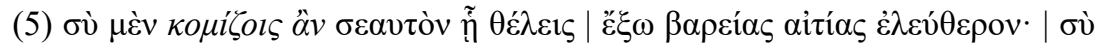

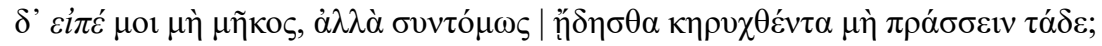
(S., Ant. 444-447) Tú tienes permiso para irte adonde quieras, libre de una grave acusación. Pero tú contéstame sin rodeos, en pocas palabras, ¿sabías que se había decretado que no se podía hacer eso?

\section{Oraciones con el predicado verbal en segunda persona}

Los tres ejemplos anteriores presentan el optativo en segunda persona ${ }^{32}$. El uso de la segunda persona está vinculado, como vemos, con la convicción del hablante de que el receptor puede llevar a cabo el contenido proposicional de su acto de habla. Le supone, pues, capacidad agentiva.

La posición de poder del hablante frente a su interlocutor es variable. En ocasiones es claramente superior al interlocutor, como en (4) y en (5), pero en otras es claramente inferior. Neoptólemo, por ejemplo (3), trata a Filoctetes antes de que se desvelen sus verdaderas intenciones con el respeto que merece un hombre maduro que participó en la guerra de Troya y al que, no olvidemos, debe ganarse por el bien del ejército griego.

También Hilo se dirige a Heracles, su padre, mediante el optativo potencial. En este caso el joven utiliza la expresión ò̀...$\mu \alpha \dot{\theta} \theta o r \varsigma$, evitando $\mu \alpha \dot{\theta} \theta \varepsilon$,

${ }^{30}$ Moorhouse 1982, p. 231 y Lloyd 2006, p. 235 consideran que las palabras de Creonte hacia el guardián tienen un tono más bien despectivo, y no cortés. En nuestra opinión, sin embargo, el contexto invita a pensar que el rey dedica al guardián unas palabras educadas como premio al deber cumplido y, al mismo tiempo, como recurso para subrayar el tono irrespetuoso con el que se dirige a Antígona. Es posible que debamos entender las palabras de Creonte como muestra de hipercortesía, pero, de momento, no tenemos datos suficientes para trazar la frontera entre el optativo de cortesía y el de hipercortesía en la tragedia.

${ }^{31}$ El imperativo es, obviamente, más directo que el optativo, pero eso no significa que siempre sea una fórmula de descortesía. Es más, las expresiones directas son neutras en algunos contextos, como, por ejemplo, cuando el hablante se halla en una situación de peligro. El valor pragmático del imperativo en Sófocles se tratará en trabajos posteriores.

${ }^{32}$ Los ejemplos en segunda persona son Ai. 213, Ai. 218, Ant. 444, Ant. 1339, El. 637, OC 580, OT 570, OT 1045, OT 1445, Ph. 674, Tr. 624 y Tr. 1154. 
fórmula más directa. Nos hallamos ante expresiones que inciden en el efecto perlocutivo del acto de habla ${ }^{33}$ :

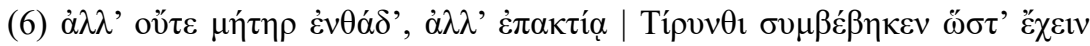

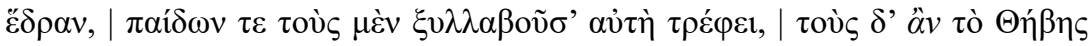

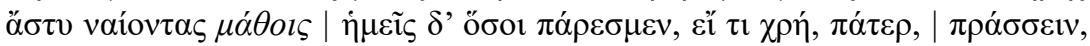

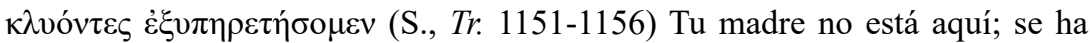
marchado a la costera Tirinto para vivir allí. Y sobre tus hijos, a unos se los ha llevado ella misma para criarlos, y deberías saber que los otros están viviendo en la ciudad de Tebas. Pero nosotros, los que estamos presentes, si hay algo que hacer, padre, atenderemos a tus palabras y las obedeceremos.

Otro ejemplo nítido del uso del optativo potencial por parte de un hablante en situación de inferioridad frente al receptor del mensaje es el siguiente, en el que Clitemnestra ruega a Apolo que cumpla sus deseos:

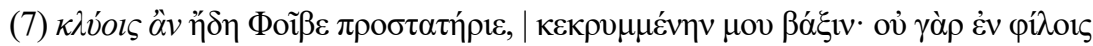
| ó $\mu \tilde{0} \theta$ os ... (S., El. 637-639) Escúchame, por favor, protector Apolo, aunque haga mi súplica a escondidas. Mis palabras no se pronuncian ante amigos.

La posición de poder variable del hablante frente a su interlocutor no es, en absoluto, sorprendente, ya que el griego no cuenta con formas de deferencia que permitan al hablante señalizar distancia o respeto ${ }^{34}$. Por lo tanto, la forma habitual para dirigirse al interlocutor es la segunda persona, sea cual sea la relación de poder y de confianza que en ese momento se tenga con él.

El optativo tampoco determina, como hemos visto en $\S$ III, el grado de coerción que se ejerce sobre el receptor. El hablante considera a su interlocutor capacitado para llevar a cabo el contenido proposicional de su acto de habla; el interlocutor, a su vez, entiende sin dificultad, tal y como confirma su reacción en todos los casos, el carácter directivo del mensaje ${ }^{35}$. El optativo

33 Se trata, en términos de Risselada 1993, p. 271, de expresiones metadirectivas. Según la autora, las expresiones metadirectivas tienen siempre un carácter enfático, pues subrayan la responsabilidad del receptor del mensaje en la realización del estado de cosas.

${ }^{34}$ Como sabemos, el griego no tiene pronombres específicos, como usted, del español, y tampoco presenta un uso de deferencia en determinados pronombres, como es el caso de vous en francés, por ejemplo.

${ }_{35}$ En las tragedias analizadas, el interlocutor tiene siempre las reacciones esperables frente a un acto de habla directivo: llevar a cabo lo que se le pide o no hacerlo. 
no es, pues, una fórmula off record poco transparente que el hablante reserve para situaciones en las que otra expresión podría poner en peligro la comunicación armoniosa con su interlocutor ${ }^{36}$. Se trata, más bien, de una fórmula convencional de cortesía de significado inequívoco que el hablante utiliza en situaciones en las que desea ser «políticamente correcto» ${ }^{37}$, es decir, mostrar el comportamiento que se espera de él en ese momento ${ }^{38}$.

La segunda persona pasa a ser una fórmula off record, sin embargo, cuando el hablante utiliza en su mensaje un predicado que no presupone control por parte del sujeto y que, además, presenta un significado alejado de la acción que se espera del interlocutor. En estos casos el carácter directivo del acto de habla resulta más opaco y, de hecho, el receptor puede permitirse no reaccionar ante él sin que su comportamiento resulte ni llamativo ni incómodo. Veamos un ejemplo.

Estamos ante el diálogo que mantienen en Edipo Rey el corifeo, Yocasta, el mensajero, que fue quien recibió al pequeño Edipo de manos de un pastor, y el propio rey. Edipo está intentando averiguar la identidad del pastor que se apiadó de él y lo salvó de la muerte cuando había de ser abandonado. Le pregunta al pastor, pero este, ante la gravedad de la situación, intenta desviar la pregunta hacia el coro. Para ello utiliza una expresión potencial que no lo compromete en absoluto y que, al mismo tiempo, puede ser ignorada por el interlocutor, si este lo desea. De hecho, los miembros del coro no reaccionan, pero Edipo, que entiende perfectamente la fuerza ilocutiva del mensaje, les pregunta de forma directa:

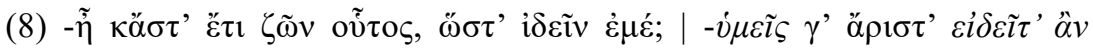

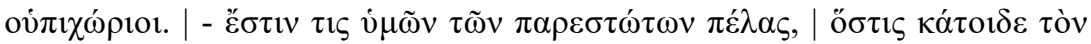

${ }^{36}$ Sobre el carácter más o menos indirecto o más o menos explícito de las expresiones de cortesía véanse, entre otros, Haverkate 1979, pp. 103-106.

${ }^{37}$ Este punto se tratará con más detalle en trabajos futuros, llevando a cabo un análisis contrastivo entre el optativo, el imperativo y el subjuntivo.

${ }^{38}$ Culpeper y Qian 2019, pp. 7-8 hacen notar cómo el hablante se ajusta con frecuencia a fórmulas rutinarias de cortesía para evitar el conflicto innecesario. Eso no significa que se esfuerce en mejorar la relación con su interlocutor, sino que procura, sin más, mantenerla y no ponerla en peligro. Sobre la conveniencia de utilizar determinadas fórmulas, y no otras, ante un interlocutor dado o en una situación dada recordemos el testimonio de Diógenes Laercio (D. L. 9.53): al parecer, Protágoras criticaba a Homero por dar órdenes a la Musa en imperativo, en lugar de dirigirse a ella mediante ruegos o deseos. 


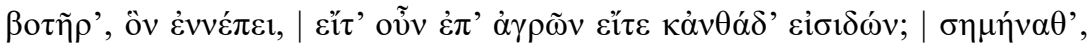

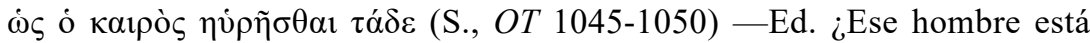
vivo todavía para que yo lo pueda ver? - Me. Vosotros, que sois de aquí, sois quienes mejor deberíais saberlo. —Ed. ¿Hay alguien de los aquí presentes que conozca al pastor del que habla?, ¿alguien que lo haya visto en el campo o por aquí? Que lo diga, que ha llegado el momento de descubrirlo todo.

\section{Oraciones con el predicado verbal en primera o en tercera persona}

Como acabamos de señalar, el uso de la segunda persona no está vinculado a un determinado estatus del hablante frente a su interlocutor en el momento del acto de habla ${ }^{39}$. Distinta es la situación en el caso de la primera y la tercera persona.

En efecto, en el material analizado, los personajes que utilizan la primera y la tercera persona para solicitar algo a su interlocutor de forma sincera se hallan en una posición de inferioridad respecto a é $1^{40}$. En estos contextos, el hablante formula ruegos o sugerencias o bien pide permiso para hacer o decir algo. Se trata, además, de situaciones en las que el personaje en cuestión intenta transmitir un mensaje que no es baladí y que, por tanto, puede ser entendido por su receptor como una clara amenaza. Esta amenaza atenta contra la intimidad y la libertad de acción del interlocutor, es decir, contra su imagen negativa. Por tanto, los esfuerzos del hablante se dirigen, sobre todo, a reducir la implicación del interlocutor en el cumplimiento del contenido del mensaje. Para ello, el hablante puede optar por maximizar su propia implicación en el acto de habla, asumiendo toda la responsabilidad de su contenido; en ese caso, acudirá a formas verbales de primera persona. Ahora bien, el hablante puede considerar que su acto de habla no solo pone en peligro la imagen negativa del interlocutor, sino también su propia imagen positiva, es decir, la posibilidad de generar o mantener un vínculo de solidaridad con el

${ }^{39}$ Drummen 2013, pp. 90-91, por el contrario, llega a la conclusión de que el optativo de segunda persona solo es utilizado por hablantes en una posición de poder.

${ }^{40}$ En $O C$ 826, Creonte, dirigiéndose a unos guardianes, utiliza el optativo potencial. Estamos, sin embargo, ante una excepción solo aparente, ya que el tono irónico del rey es evidente. Como ya se ha comentado, este tipo de ejemplos se dejan, de momento, fuera de consideración. 
interlocutor. En esta situación, combinará las estrategias de alejamiento del interlocutor del cumplimiento del acto de habla directivo que implican sus palabras con estrategias que le permitan distanciarse de su propio acto de habla; el uso de formas verbales en tercera persona y de formas verbales de diátesis pasiva en primera persona serán sus recursos ${ }^{41}$. El uso de oraciones de tipo asertivo, con frecuencia mitigadas, no ha de sorprendernos, ya que es muy característico de la cortesía off record ${ }^{42}$ : el hablante afirma algo o especula sobre ello para provocar una reacción concreta en su interlocutor ${ }^{43}$.

\subsection{Maximización de la implicación del hablante: oraciones con el predicado verbal en primera persona}

En las tragedias de Sófocles, el uso de la primera persona en los contextos analizados refleja, en general, tres estrategias distintas que tienen como fin desplazar hacia el propio hablante la responsabilidad del interlocutor en el cumplimiento del contenido del acto de habla ${ }^{44}$. Ahora bien, estas tres estrategias reflejan un grado de compromiso del hablante variable y no siempre igual de explícito ${ }^{45}$ :

1. El hablante utiliza un verbo de voluntad con el contenido de lo que espera que haga su interlocutor (9). Recurre, pues, a una expresión performativa ${ }^{46}$.

${ }^{41}$ Yamamoto 2006, p. 24 propone una estrecha relación entre la animación y la intención, rasgos prototípicos de la agentividad, y la responsabilidad. La responsabilidad es un rasgo esencial en los contextos que estamos analizando ahora.

${ }^{42}$ Cf., entre otros, Briz y Albelda 2013, pp. 299-302, para el español. Para el latín, cf. Risselada 1993, p. 92, que atribuye a estos actos de habla una «(partially) implicit performance of a directive». Para el caso concreto de Sófocles, véase Catrambone 2016, pp. 280 ss.

${ }^{43}$ Pensemos en una oración como No estaría mal encender la calefacción, dicho, por ejemplo, por alguien que se encuentra en una sala con dos personas más.

${ }^{44}$ De momento, dejamos fuera de consideración ejemplos como el siguiente, en el que el hablante anuncia un propósito inmediato que va llevar a cabo él mismo: $\chi \omega \rho о \tilde{\mu} \mu$ '

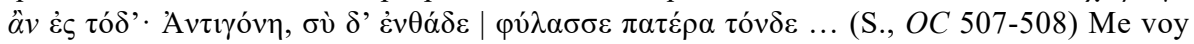
a hacerlo (sc. dedicar una plegaria a las Euménides). Antígona, tú quédate aquí y cuida a nuestro padre.

${ }^{45}$ Los siguientes pasajes permiten observar una de estas tres estrategias: Ai. 525-526 (estrategia 1), Ai. 1339 (estrategia 2), OT 95 (estrategia 3), OT 205 (estrategia 1), OT 282 (estrategia 3) y $P h .517$ (estrategia 2).

${ }^{46}$ Las expresiones performativas han recibido mucha atención, pues su análisis sintáctico y pragmático plantea serias dificultades. De hecho, las expresiones performativas 
2. El hablante expresa lo que él haría en las circunstancias en las que se encuentra su interlocutor (10).

3. El hablante pide permiso para hablar, pero no indica cuál es el contenido de la petición que quiere hacer (11).

La estrategia 2 da lugar a actos de habla más ambiguos e indirectos que la 1. Se trata de una fórmula off record que, en teoría, permite al interlocutor no darse por aludido. La estrategia 3 se plasma en lo que se conoce como acto de habla preparatorio, es decir, en un acto de habla cuyo objetivo esencial es ganarse el favor del interlocutor antes de la formulación de un acto de habla comprometido, en este caso directivo ${ }^{47}$; no se trata, pues, de un acto directivo en sentido estricto.

Centrémonos en tres ejemplos.

En el primero de ellos, el corifeo toma la palabra después de oír a Tecmesa lamentarse por la suerte que la espera si Ayante decide suicidarse. La situación es crítica, y se siente en la necesidad de intervenir y hablar con Ayante. Eso sí, el corifeo subraya su implicación y responsabilidad en el contenido del acto de habla acudiendo no solo al uso de una construcción performativa $^{48}$, sino también al pronombre غ̇үó:

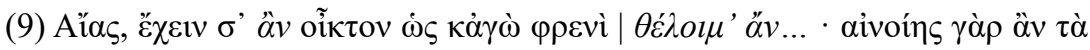
$\tau \tilde{\eta} \sigma \delta \delta^{\prime} \ddot{z} \pi \eta$ (S., Ai. 525-526) Ayante, yo querría que sintieras en tu corazón la misma compasión por ella que siento yo, pues aprobarías sus palabras.

En (10) vemos a un corifeo compadecido ante Filoctetes, quien suplica a Neoptólemo que lo lleve con él y no lo condene a la soledad y el dolor. El corifeo, que no se atreve a formular directamente su ruego, intenta que Neop-

tienen un carácter asertivo, pero implican un cambio extralingüístico, cambio que en algunos casos se produce con la formulación misma del acto de habla (cf. Searle 1989, p. 553). Risselada 1993, pp. 247-258 atribuye un valor directivo a las expresiones performativas del tipo de (9).

${ }^{47}$ En español, oraciones como Se me está ocurriendo una cosa funcionan con frecuencia como enunciados preparatorios de actos de habla directivos. Sobre los enunciados preparatorios véanse, entre otros, Kerbrat-Orecchioni 2005, p. 68 y Briz 2007.

${ }^{48}$ Las expresiones performativas son empleadas por el hablante para garantizar la verdad y sinceridad de sus palabras. Tampoco cabe una interpretación incorrecta de lo que está diciendo (cf. Searle 1989, p. 539). Se trata, por tanto, de un medio eficaz de subrayar el protagonismo de uno y minimizar el del interlocutor. 
tólemo cumpla los deseos del pobre enfermo. Además de expresarse con cautela, el corifeo presenta sutilmente la decisión de llevarse a Filoctetes como un acto de piedad que podría librar a Filoctetes de la ira de los dioses. Al igual que en el ejemplo anterior, el corifeo utiliza el pronombre $\dot{\varepsilon} \gamma \omega ́$ para subrayar su responsabilidad:

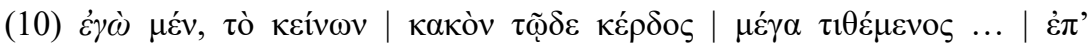

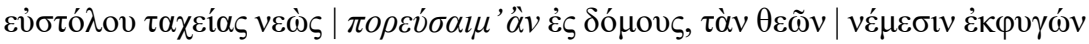
(S., $P h .513-518)$ Yo, convirtiendo el mal de ellos en una gran ganancia para él, lo llevaría a su casa en una nave bien equipada y rápida. Así escaparía a la ira de los dioses.

Pasemos al último pasaje. En él asistimos a un diálogo esencial entre el corifeo y Edipo. El corifeo acaba de jurar al rey que desconoce la identidad del asesino de Layo. Como Apolo se niega a expresarse con claridad y desvelar el nombre del culpable, al corifeo se le ocurre llamar a Tiresias. Pero no se atreve a formular su petición abiertamente, así que pide permiso para sugerir algo que, de momento, prefiere no revelar. Utiliza, pues, una expresión performativa, pero no concreta el contenido de lo que quiere decir:

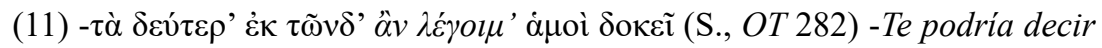
lo que me parece una segunda opción.

Como se observa en los tres pasajes que hemos seleccionado, los actos de habla en los que el hablante maximiza su implicación en el contenido de su mensaje se articulan mediante oraciones en las que se describe un estado de cosas controlado por un agente. El agente de dicho estado de cosas, que hace referencia al hablante, se codifica como sujeto.

\subsection{Minimización de la implicación del interlocutor y del hablante}

Cuando el hablante pretende formular sugerencias minimizando tanto la implicación del interlocutor como la suya propia en el contenido del acto de habla, recurre a formulaciones en las que las funciones de sujeto y de agente quedan disociadas, en mayor o menor medida, del interlocutor, pero también 
del hablante ${ }^{49}$. Esta disociación se logra mediante cuatro recursos, todos ellos propios de una cortesía verbal off record ${ }^{50}$ :

1. En la oración se elimina toda referencia al hablante. El interlocutor es identificado con una tercera persona, persona a la que se presupone capacidad agentiva (12).

2. El interlocutor es codificado en la oración como complemento agente de una construcción pasiva (13). Si hay referencia al hablante, se le atribuye un papel inactivo.

3. En la oración se elimina toda referencia semántica y sintáctica al interlocutor, pero no al hablante, que es codificado en la oración como sujeto de una construcción de diátesis pasiva, o como persona interesada en la acción verbal (14).

4. En la oración se elimina toda referencia semántica y sintáctica tanto al interlocutor como al hablante: empleo de una construcción impersonal (15).

Como vemos, la implicación del interlocutor en el contenido del acto de habla es menor en 4 que en 3; en 3, menor que en 2; en 2, por último, menor que en 1. Estas estrategias representan, por tanto, un proceso de despersonalización ${ }^{51}$ progresivo.

Pasemos a analizar algunos ejemplos.

En el siguiente fragmento volvemos a asistir al diálogo entre Edipo, Yocasta, el corifeo y el mensajero. Como hemos visto en (8), Edipo, desesperado, pregunta al coro si sabe quién fue el pastor que impidió su muerte. El corifeo, cauto, dice lo que cree saber, pero, ante lo grave de la situación, considera necesario que Yocasta corrobore sus palabras ${ }^{52}$. Se dirige a ella en

${ }^{49}$ Los pasajes son los siguientes: Ai. 1342 (estrategia 2), Ant. 240 (estrategia 3), El. 1436 (estrategia 3), El. 1440 (estrategia 4), OC 725 (estrategia 2.), OC 1565-1567 (estrategia 1) y OT 1053 (estrategia 1).

${ }^{50}$ En los recursos 1, 3 y 4 estamos ante actos de habla directivos orientados a la tercera persona o sin orientación (cf. § III). Sobre la relación entre estos procedimientos y la cortesía off record, véanse, entre otros, Brown y Levinson 1989, pp. 190-205. Sobre Sófocles, véase Catrambone 2016, pp. 188-189, que hace referencia al recurso de overgeneralization.

${ }^{51}$ Villalba 2013, p. 131, entre otros, plantea la despersonalización como un fenómeno gradual. Téngase en cuenta que en 3 se despersonaliza al interlocutor, pero se mantiene la identificación del hablante.

52 El interlocutor del corifeo es hasta ese momento Edipo, pero en la oración que analizamos ahora el verdadero destinatario del mensaje es Yocasta, que es de quien se espera una reacción. 
tercera persona, y no en segunda ${ }^{53}$, haciendo uso, además, de la litote ở $\chi$

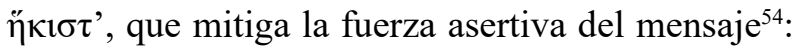

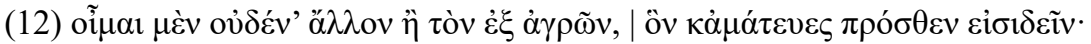

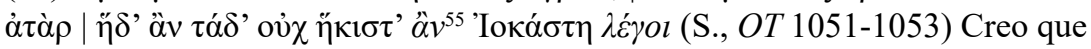
no es otro que el hombre de campo al que hace un rato querías ver. Pero esto, Yocasta, aqui presente, lo podría decir con no poca certeza.

En (13), Agamenón, que se niega a que Ayante reciba sepultura, acaba de tener un duro enfrentamiento con Teucro. Odiseo, ajeno a la disputa, aparece en escena. Tras enterarse del motivo del conflicto, intenta convencer a Agamenón para que no deje insepulto el cadáver. En una situación tan delicada, Odiseo acude primero al uso de la primera persona (v. 1339), asumiendo, de este modo, la responsabilidad de lo que está proponiendo; después, se sirve de una construcción pasiva, no activa, para hacer alusión a la deshonra de Ayante. En esta construcción se atribuye a Agamenón la función de complemento agente. Como en el ejemplo anterior, observamos una litote como recurso para reducir la fuerza asertiva del mensaje:

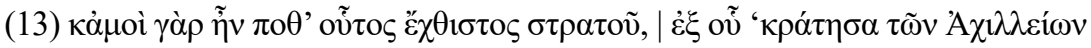

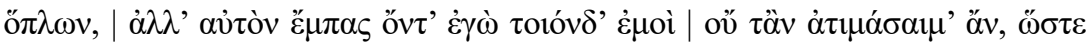

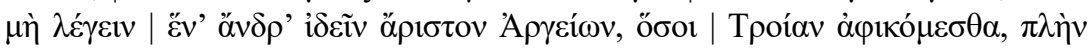

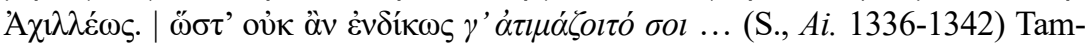
bién fue mi mayor enemigo en el ejército desde el momento en que me apoderé de las armas de Aquiles. Pero yo no deshonraría a un hombre tal hasta el punto de negar que vi en él al más valiente de cuantos argivos llegamos a Troya, excepción hecha de Aquiles. Así que sin justicia sería deshonrado por ti.

${ }^{53}$ Es Edipo quien, acto seguido, la apela en segunda persona y le pregunta directamente la información que necesita (S., OT 1054-1055).

${ }^{54} \mathrm{La}$ litote refleja con frecuencia una estrategia de mitigación (cf. Caffi 2007, p. 53). Sobre la relación entre la litote y las estrategias de cortesía, en particular las de tipo off record, véase Hoffmann 1987, p. 186.

${ }^{55}$ Sobre el valor enfático de la repetición de ớv en estos contextos véanse, entre otros, Slings 1992, p. 103 y Drummen 2013, pp. 92-102. Drummen 2013, pp. 98-101 pone en estrecha relación la repetición de ớv con la negación, a la que también atribuye un valor enfático. Se trata, en opinión de la autora, de contextos en los que el hablante rechaza una oferta. Nuestro corpus no parece confirmar todas las conclusiones a las que llega Drummen, pero es un tema que no podemos tratar aquí. 
En el siguiente pasaje nos encontramos con el guardián que ha descubierto a Antígona. Aunque no sabe la suerte que lo espera, decide acudir a Creonte para contarle que sus órdenes han sido incumplidas. El rey, que lo ve llegar apurado, le pregunta qué le ocurre. Entonces el guardián, sin ocultar la preocupación por su futuro, le dice que lo primero que quiere abordar es su situación. Como vemos, cierra sus palabras rogando al rey, de forma indirecta, que no lo castigue por un error que no ha cometido. El uso de una forma verbal en primera persona de diátesis pasiva ${ }^{56}$ nos muestra el deseo del guardián de librarse de toda responsabilidad y, al mismo tiempo, de desvincular al interlocutor del cumplimiento de su ruego. No en vano evita toda referencia al agente, que es, obviamente, Creonte. Obsérvese, de nuevo, la presencia de una litote:

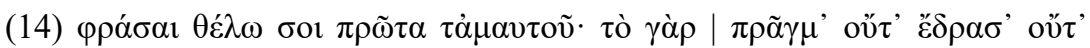

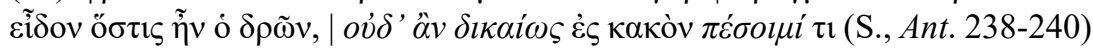
Quiero hablarte primero de lo que me atañe a mí: el hecho, ni lo hice yo, ni vi quién lo hizo. Y no sería justo que cayera yo en desgracia alguna

En el siguiente ejemplo, por último, se nos describe una situación crítica. Egisto está a punto de recibir a Orestes, dispuesto a matarlo. La función de Electra es la de conseguir que Egisto acuda al lugar donde lo espera la muerte. En ese momento el coro hace a la joven una sugerencia, con la que cree que el éxito de la empresa quedaría garantizado, y que ella va a desoír: que hable al oído a Egisto con palabras amables. Como vemos, el coro de mujeres recurre a una construcción impersonal de un verbo de modalidad deóntica. Con ello consigue dos efectos: desvincular completamente a Electra de toda responsabilidad en el cumplimiento de la acción y, al propio tiempo, conferir a sus palabras una validez general:

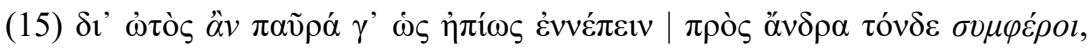

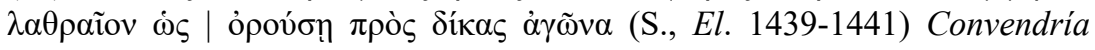
hablar al oído a este hombre en tono amable, para que, engañado, se precipite a la lucha que ha dispuesto la justicia.

Todos los recursos que acabamos de analizar tienen, desde un punto de vista sintáctico, semántico y pragmático, un mismo efecto: el de la reducción

\footnotetext{
${ }^{56}$ La morfología de $\pi \varepsilon ́ \sigma o u \mu$ es activa, pero su diátesis pasiva.
} 
de la posición del interlocutor en uno o varios parámetros de la escala de animación. En todas las lenguas naturales, los hablantes, movidos por un principio antropocéntrico, tienden a atribuir las funciones sintácticas, semánticas y pragmáticas más relevantes a los seres humanos y, dentro de los seres humanos, a sí mismos o a su interlocutor (primera persona / segunda perso$n a>$ tercera persona). En la escala sintáctica, el sujeto ocupa la primera posición; en la escala semántica, es el agente quien ocupa esta primera posición; en la escala pragmática, por último, la primera posición la ocupa el tópico, es decir, la entidad de la que se habla ${ }^{57}$.

Por lo demás, el hablante también intenta atribuirse un papel poco activo en el cumplimiento del contenido de su acto de habla. Evita, pues, asignarse la función de agente.

\section{Conclusiones}

La aplicación de la teoría de la cortesía verbal al análisis del optativo potencial en las obras completas de Sófocles permite explicar algunos usos para los que una aproximación sintáctica y semántica no tienen respuesta. En el caso concreto del funcionamiento del optativo potencial en actos de habla con un valor directivo inequívoco o un valor directivo implícito, el presente trabajo permite extraer las siguientes conclusiones:

1. El optativo potencial expresa tanto actos de habla directivos enfocados hacia los intereses del hablante como actos de habla directivos enfocados hacia los intereses del interlocutor.

2. En su uso en segunda persona, el optativo no determina ni el grado de coerción que el hablante ejerce sobre su interlocutor ni la posición de poder del hablante frente a él. En la mayor parte de los casos, el optativo no es una expresión directiva off record poco transparente, sino, más bien, una fórmula convencional de cortesía de significado inequívoco. Frente a ello, el uso de la primera y tercera personas sí se asocian con una cortesía de tipo off record: el hablante recurre a actos de habla cuyo carácter directivo no es, ni mucho menos, evidente, lo que permite al receptor una libertad de reacción considerable.

${ }^{57}$ Sobre la escala de animación véanse, entre otros, Keenan y Comrie 1977, Itagaki y Prideaux 1985 y Filimonova 2005. 
3. En los pasajes analizados, el uso del optativo potencial en primera o en tercera persona se observa en boca de personajes con una posición de inferioridad que han de transmitir al interlocutor un mensaje que puede ser entendido por este como una clara amenaza a su imagen negativa. Los esfuerzos del hablante se dirigen, por tanto, a reducir la implicación del interlocutor en el cumplimiento del contenido proposicional de tal mensaje. Ahora bien, en ocasiones la preocupación del hablante no solo se centra en preservar la imagen negativa del interlocutor, sino también su propia imagen positiva, es decir, su deseo de mantener o de generar un vínculo de solidaridad entre él y el interlocutor.

4. Cuando los personajes focalizan su interés en preservar la imagen negativa de su interlocutor, acuden al uso de la primera persona; con ello desplazan hacia sí mismos la responsabilidad del interlocutor en el contenido del acto de habla y, por tanto, también en su cumplimiento. En estos casos, el hablante se sirve de oraciones en las que se codifica a sí mismo como sujeto agente.

5. Cuando los personajes focalizan su interés en preservar no solo la imagen negativa del hablante, sino también su propia imagen positiva, formulan oraciones en las que las funciones de sujeto y de agente quedan disociadas, en mayor o menor medida, tanto del interlocutor como de sí mismos. En todos los casos se reduce la posición del interlocutor en la escala de animación en uno o varios parámetros.

\section{BIBLIOGRAFÍA}

Allan, R. 2017: «The History of the Future: Grammaticalization and Subjectification in Ancient Greek Future Expressions», en Lambert, F., Allan, R. y Markopoulos, Th. (eds.), The Greek Future and its History, Lovaina, pp. 43-72.

Briz, A. 2007: «Para un análisis semántico, pragmático y sociopragmático de la cortesía atenuadora en España y América», LEA 29 (1), pp. 5-40.

Briz, A. y Albelda, M. 2013: «Una propuesta teórica y metodológica para el análisis de la atenuación lingüística en español y portugués. La base de un proyecto en común (ES.POR.ATENUACIÓN)», Onomazein 28, pp. 288-319.

Brown, P. y Levinson, S. C. 1987: Politeness: Some Universals in Language Usage, Cambridge.

Caffi, C. 2007: «Mitigation», Studies in Pragmatics 4, Oxford.

Catrambone, M. 2016: «Off-Record Politeness in Sophocles», Journal of Politeness Research 12 (2), pp. 173-195. 
Chantraine, P. 1997²: Grammaire homérique II: Syntaxe, París.

Clark, H. y Brenann, S. 1991: «Grounding in Communication», en Resnick, B. Levine, J. M. y Teasley, S. D. (eds.), Perspective on Socially Shared Cognition, Washington, pp. 127-149.

Clark, H. y Carlson, Th. 1982: «Hearers and Speech Acts», Language 58, pp. 332-373.

Conti, L. 2017: «On the Non-Prototypical Uses of Adverbs in Homer: Analysis of $\eta \delta\lceil »$, en Pocchetti, P. y Logozzo, F. (eds.), Ancient Greek Linguistics: New Approaches, Insights, Perspectives, Berlín-Boston, pp. 119-132.

Crespo, E., Conti, L. y Maquieira, H. 2003: Sintaxis del griego clásico, Madrid.

Culpeper, J. 1996: «Towards an Anatomy of Impoliteness», Journal of Pragmatics 25, pp. 249-367.

Culpeper, J. y Qian, K. 2019: «Communicative Styles, Rapport, and Student Engagement: An Online Peer Mentoring Scheme», Applied Linguistics 2019: 0/0, pp. 1-32.

Denizot, C. 2011: Donner des ordres en grec ancien. Étude linguistique des formes de l'injonction, París.

Drummen, A. 2013: «A Constructionist Approach to the Potential Optative in Classical Greek Drama», Glotta 89, pp. 6-108.

Filimonova, E. 2005: «The Noun Phrase Hierarchy and Relational Marking: Problems and Counterevidence», Linguistic Typology 9, pp. 77-113.

Haverkate, H. 1979: Impositive Sentences in Spanish, Ámsterdam.

Haverkate, H. 1984: Speech Acts, Speakers and Hearers, Ámsterdam.

Hoffmann, M. E. 1987: Negatio Contrarii: A Study of Latin Litotes, Assen.

Itagaki, N. y Prideaux, D. (1985): «Nominal Properties as Determinants of Subject Selection», Lingua 66, pp. 135-149.

Kadar, D. Z. 2019: «Introduction: Advancing Linguistic Politeness Theory by Using Chinese Data», Acta Linguistica Academica 66 (2), pp. 149-164.

Keenan, E. y Comrie, B. 1977: «Noun Phrase Accessibility and Universal Grammar», Linguistic Inquiry 8, pp. 63-99.

Kerbrat-Orecchioni, C. 1996: La conversation, París.

Kerbrat-Orecchioni, C. 2004: «Il fait vraiment chaud aujourd'hui! Vous voulez boire quelque chose? Le 'travail des faces' dans l'échange initié par une offre», en Auchlin, A. et al. (eds.), Structures et discours. Mélanges offerts à Eddy Roulet, Quebec, pp. 417-432.

Kerbrat-Orecchioni, C. 2005: Le discours en interaction, París.

Kienpointner, M. 1997: «Varieties of Rudeness: Types and Functions of Impolite Utterances», Functions of Language 4, pp. 251-287.

Kühner, R. y Gerth, B. 1898: Ausführliche Grammatik der griechischen Sprache, II: Syntax, Hannover-Leipzig. 
Lloyd, M. 2006: «Sophocles in the Light of Face-Threat Politeness Theory», en Rijksbaron, A. y de Jong, I. (eds.), Sophocles and the Greek language: Aspects of Diction, Syntax and Pragmatics, Leiden-Boston, pp. 225-239.

Lloyd, M. 2012: «Sophocles the Ironist», en Markantonatos, A. (ed.), Brill's Companion to Sophocles, Leiden, pp. 563-577.

Locher, M. A. 2004: Power and Politeness in Action, Disagreements in Oral Communication, Berlín-Nueva York..

Locher, M. A. y Watts, R. 2005: «Politeness Theory and Relational Work», Journal of Politeness Research 1, pp. 9-33.

Moorhouse, A. C. 1982: The Syntax of Sophocles, Leiden.

Risselada, R. 1993: Imperatives and Other Directive Expressions in Latin, Ámsterdam.

Searle, J. 1975: «Indirect Speech Acts», en Cole, P. y Morgan, J. L. (eds.), Syntax and Semantics, 3: Speech acts, pp. 59-82.

Searle, J. 1989: «How Performatives Work», Linguistics and Philosophy 12, pp. 535-558.

Slings, S. R. 1992: «Written and Spoken Language: An Exercise in the Pragmatics of the Greek Language», Classical Philology 87, pp. 95-109.

Spencer-Oatey, H. 2008: «Face, (Im)politeness and Rapport», en Spencer-Oatey, H. (ed.), Culturally Speaking: Culture, Communication and Politeness Theory, Nueva York, pp. 11-47.

Van Emde Boas, E., Rijksbaron, A., Huitik, L. y de Bakker, M. 2019: Cambridge Grammar of Classical Greek, Cambridge.

Villalba, C. 2013: «La impersonalidad como recurso atenuante en los juicios orales», en Cabedo, A., Aguilar, M. J. y López-Navarro, E. (eds.), Estudios de lingüistica: investigaciones, propuestas y aplicaciones, Valencia, pp. 121-135.

Watts, Richard J. 2003: Politeness, Cambridge.

Yamamoto, M. 2006: Agency and Impersonality: Their Linguistic and Cultural Manifestations, Ámsterdam.

Fecha de recepción de la primera versión del artículo: 13/12/2019

Fecha de aceptación: 15/04/2020

Fecha de recepción de la versión definitiva: 14/06/2020 